\title{
An Exploration On The Development Of The IT Management System In Taiwan's Banking Industry: From The Marketing Perspectives.
}

Cho-Pu Lin, Northwestern Polytechnic University, USA

Dr. Yann-Haur Huang, Northwestern Polytechnic University, USA

Chien-Ting Chen, Fortune Institute of Technology College, Taiwan, Republic of China

Hsing-Yun Chang, Northwestern Polytechnic University, USA

\begin{abstract}
The focal point adopted in the present study is Customer Relationship Management (CRM) and its adoption in Taiwan's banking industry. Since the current challenge banks are facing is in implementing and supporting new technological solutions that will enable them to be more responsive and flexible to their clients, a quantitative research methodology was employed in the present study in an attempt to answer the following research question: What are the critical factors that explain the degree of success in the deployment of CRM systems in Taiwan's banking industry? First, based on the findings from the previous studies, an exploratory study consisting of focus-group interviews was conducted to uncover the nature of the problems confronting the banks in adopting CRM. Second, based on the findings from this preliminary investigation, a quantitative analysis using survey and statistical methods was conducted to identify possible answers to the research question. The research done with the present study has uncovered a number of factors which can be used to guide companies for a successful CRM deployment. These factors include primacy of customer service, customizing CRM functions/modules, discovering customers' needs, maintaining employee's moral, conducting a decision support system. If the major goal of implementing a CRM system is to improve the overall CRM deployment, the management in Taiwan's banking industry should then emphasize three of two factors: primacy of customer service and customizing CRM functions/modules.
\end{abstract}

Keywords: customer relationship management; Taiwan; banking industry; business strategies; CRM; enterprise information systems

\section{INTRODUCTION}

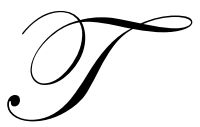

he focal point adopted in the present study is Customer Relationship Management (CRM) and its adoption in Taiwan's banking industry. The concept of CRM and its benefits have been widely accepted. Kincaid (2003, p. 47), for instance, states "CRM delivers value because it focuses on lengthening the duration of the relationship (loyalty)." Motley (2005) found that satisfiers keep the customers in the bank while dissatisfiers eventually chase them out. Earley (2003) highlights the necessity of holistic CRM strategies for every company because nowadays even the most solid brand names could no longer secure lasting customer loyalty. In view of these observations, the authors of the present study believe that customer relationship management is critical for any service firms, including the banks.

\section{Rational Of The Study}

Nowadays, a sacrosanct tenet for all businesses is to keep their existing customers, and one way to keep existing customers is to satisfy them. According to the " $20 / 80$ " rule in marketing, $80 \%$ of the sales comes from $20 \%$ of the customers. In addition, Peppers and Rogers (1993) maintain that the costs of discovering new customers are six to nine times that of keeping existing customers. Thus, for a business to survive, it is indeed critical to cultivate loyalty 
with existing customers.

According to K. L. Lu (2000), through the adoption of CRM systems, companies could find best customers, keep existing customers, maximize customer value, and develop effective risk management. In addition, successful CRM will generate huge profits for companies through improved customer retention. A major challenge banks are facing today is in implementing new technological solutions that provide greater responsiveness and flexibility to their clients. Many corporations are now conducting transactions with fewer banks. As Dobbins (2006) pointed out, the challenge for all banks, large and small, comes from not only creating a center of excellence with established international standards of communication, but also reconstructing and automating their business processes for efficiency. Coffey and Palm (2005) found that, in a bank, it was not easy to integrate data from one system into another for the data were used differently in different systems. This problem typically occurs when profitability data are integrated into a CRM. In addition, the extent to which a CRM is adopted is an issue: currently, relatively few firms have already adopted a CRM solution. Harrison and Hollingsworth (1991) argue that it is very important for the banking industry to maintain its customer relationship.

Similarly, Nagar and Rajan (2005, p. 905) admonish, “...in banking terminology, the value to the bank of its long-term relationships with its depositors is called the core deposit intangible and is an important asset." In Taiwan's banking industry, the adoption of CRM faces another hurdle. That is, few banks in Taiwan have much of an understanding of the true nature of CRM. An ARC Constants Ltd. survey indicates that $90 \%$ of companies in Taiwan (most of which were in the banking industry) knew about CRM, yet only 64\% of them understood the intension of CRM. Furthermore, only $10 \%$ of Taiwan's banking industry has already established the CRM system.

Hence, for CRM adoption in Taiwan's banking industry, there is still a lot of room for growth (F. H. Lin and Lin, 2002). Huang and Lu (2003, p. 115) say, "Recently, the competitive environment of the local banking industry becomes acute because so many branches set up in the past few years and the effectiveness after Taiwan turned into the member of World Trade Organization (WTO). Implementing a CRM system becomes a hot issue for the local banks to consider." Thus, the authors of the present study believe that an exploration of the CRM adoption in Taiwan's banking industry, at this point, is a worthwhile undertaking. Huang and $\mathrm{Lu}$ (2003) also argue that Taiwan's financial institutions, in this customer-oriented generation, should not formulate their operational strategies solely from a product-oriented prospective. Instead, they need to accurately categorize customers' preferences and pinpoint the potential needs of their customers. So doing, they will be able to promote their financial products with receptive customers.

Predictably, then, in Taiwan's banking industry, the focus of competition strategies will soon shift from "products" to "customers." Thus, integrating front and back processes and understanding the intension and implementation of Customer Relationship Management should become an urgent task for Taiwan's banking industry in way of customizing its financial products for the customers. Research on this topic, such as exemplified in the present study, should thus be deemed a timely effort.

\section{LITERATURE REVIEW}

\section{Over-All Strategies Versus Customer Services}

All organizations, including those in the banking industry, should have a clear picture of their goals and objectives for adopting a CRM system, and they will need to create a set of selection criteria based on these goals and objectives in choosing or developing the best CRM package for their business. In addition, a firm should have a clear goal of their CRM vision and strategies before discussing the technology.

H. P. Lu, Hsu and Hsu (2002) found that, when implementing a CRM system, Taiwan's banking industry would normally focus on the customer-service system rather than on the overall strategies. These writers advise, "The bank that has established CRM systems should not treat CRM as a customer-service system, but to use it with a broader view" (p. 540). Teng (2003) also points out that the CRM adoption in Taiwan's banking industry is not as deep 
as in its U.S. counterpart. In addition, the application of CRM systems in Taiwan has recently been limited to customer-service centers or call centers. It appears, then, that while the focus of Taiwan's banking industry is on customer services, in United States it is on "overall strategies." The present study explores the relationship between "primacy of customer service over strategies" and the adoption of CRM in Taiwan's banking industry.

\section{Customization Of CRM Functions/Modules}

Chang and Liu (2005) believe that customization is a key to gaining the emotional promises from the customers in Taiwan's banking industry and that such promises can increase customer loyalty (i.e., decreasing customer churn rate). Due to the fast-changing financial environment, competitiveness, and high customer churn rates, Taiwan's banking industry should focus on long-term customer relationships and strive to increase customer retention rate. Li (2003) found that, in order to enhance the customer services, the CRM systems should be adjusted when a company adopts them. In other words, companies should "customize" their CRM systems according to the common demands of groups of customers. If the customization of the CRM system cannot satisfy the customers, companies could further consider "personalizing" their CRM systems. "If a bank has effective ability to deal with a contingency or emergency and could provide professional financial plans as well as innovative services with its financial products, these customization functions could help increase the reorganization of customer values," said Chang and Liu (2005, p. 510). Liao (2003) suggests that companies, when adopting CRM systems, should emphasize customer differentiation, customer loyalty, customer lifetime values, one-to-one marketing, and customization. Born (2003) argues that "the greater the CRM functionality, the less customization of the CRM system required" (p. 1). Obviously, there is a difference in customization in the banking industry between the United Sates and Taiwan. Companies in Taiwan would more likely customize their CRM systems in order to satisfy their customers' needs. However, in U.S., customization is not as widespread. Thus, a main goal of the present study is to explore the relationship between customization of CRM functions/modules and the adoption of CRM in Taiwan's banking industry.

\section{Customer Value Management}

The term "customer value management" can also be taken as an element of CRM. Mrazek (2001) defines customer value management (CVM) as "... a process that refines and leverages the benefits of customer relationship management." A bank may want to employ customer value management to measure and understand the current and future value of their customers. Allen (2002, p. 11) illustrates the importance of CVM when saying, "Understanding customers is the first step to achieving profitable business through customer value management. To do this, you must discover what your customers' needs and value expectations are." Dorfman (2006) also stresses the strong demand of the banking industry for customer value management, asserting that most banking executives realize the working of the $80 / 20$ (perhaps 90/10) rule on their industry.

Chang and Lin (2002) found that the degree of requirement and cognition of information quality among financial organizations in Taiwan was very high because those organizations relied on this information to understand the demands of their customers. Moreover, through the adoption of CRM systems, financial organizations can understand consumers' behavior thoroughly before providing products and services to them. Furthermore, as with these financial organizations, Taiwan's banking industry has a keen awareness of the importance of information quality because their credit-card services compare with those provided by other industries. Through the application and use of credit cards, the banking industry can gain more details and a deeper understanding of their customers while interacting with them.

Dorfman (2006) assesses that the banking industry has an advantage of gleaning both current customers and potentially profitable future customers. That is, compared to most other industries, banking has richer customer databases consisting of transaction files, balance positions, call-center records, etc. In the same vein, Streeter (1999) states that most banks would agree that they emphasize providing values to their customers. Dorfman (2006) has put forth an effective approach to gaining the loyalty of the identified highest-value target segments and tapping their vast profit potentials for the banking industry. First, banks may need to conduct an audit of their competitive strengths and advantages (e.g., products, services, brand, etc.) to differentiate themselves. Second, there should be interviews with 
the target customers to capture the precise insights on their financial needs and desires so that the bankers can formulate a value proposition that both resonates with these customers and aligns with the corporate assets. A reasonable conclusion from this literature is that discovering customers' needs and providing values to them is critical to CRM adoption in Taiwan's banking industry.

\section{Customer Churn Management}

Many researchers have isolated customer churn as a significant issue in the banking industry. Fuller (2005, p. 47), for example, found that "in some cases, banks lose 40 percent of new customers before these customers' first-year anniversary." Moreover, Kish (2000, p. 31) found that “...each year banks lose between 15 and 25 percent of their customers and then spend millions of dollars luring defectors back and recruiting new customers." Thus, it is clear that customers are much easier to lose than to gain. The banking industry is suffering high customer attrition rates, an intractable problem in the industry.

Fuller (2005) sets the banks' average annual consumer attrition at 8 to 12 percent. Robert and Markey (2003) notes that if a bank wishes to lay a solid foundation for long-term relationships with its customers and accelerate its top-line growth, it would need to engage its customers as early as possible; the first days and months are critical. Robert and Markey (p. 7) assesses that, on the average, the U.S. banks lose about $32 \%$ of its new customers during the first year of service. Penny (1993, p. 70) presents a unique view on customer retention: employee longevity means customer longevity. Clearly, this assumption is grounded on the premise that the employees are necessarily competent and personable. As many researchers have found, the attitude and morale of employees in a bank are a key to customer satisfaction. Any mistake in the interaction between front-line employees and customers will negatively influence customer satisfaction.

Gulledge (1991, p.48) comments, "If your front-line employees are very dissatisfied, your customers probably aren't very happy either, unless you are fortunate enough to have few employees covering other deficiencies." Hall (2007, p. 17) suggests that banks need to develop a staff (and a brand) that loves the business and helps its customers more than the competition. Lian (1993) suggests an approach to improve employees' morale in the strategic planning process. According to Lian, giving employees of a bank a chance to participate in the decision-making process and upgrading their working environment can encourage them to be more dedicated and creative. Overall, this discussion suggests that the ways in which employees are hired do have a strong bearing on a bank's customer loyalty. The material reviewed thus far clearly suggests that keeping employee longevity and maintaining employee morale would be critical for CRM adoption in Taiwan's banking industry. Parenthetically, employee longevity here means the length of career life of a bank employee.

\section{Customer Risk Management}

Since a bank offers countless daily services--such as offering credit cards, loans, mortgages — it is very risky for it to offer such services to customers they know nothing about. It is generally acknowledged that banks need to ensure the reliability of their customers (Hormazi and Giles, 2004). The concept here is simple: the banking industry has a need to reduce the risks from issuing credit cards or loans to customers who are likely to default. An example, given by Cocheo (2005), is of a bank that found a borrower appealing until receiving a court notice saying the customer had filed a bankruptcy. As a solution to problems such as this, the artificial neural network (ANN) has been widely used.

According to Fadlalla and Lin (2001), an ANN is a technology using a pattern-recognition approach that has been employed successfully in many business applications, including those in the U.S. banking industry. According to Turban, Aronson, and Liang (2004), an ANN is able to learn patterns in the data presented during training and will automatically apply what it has learned to new cases. One important application of ANN is in bank loan approvals because an ANN can learn to identify potential loan defaulters from the ascertained patterns. Turban et al. further observe that one of the most successful applications of an ANN is in detecting unusual credit spending patterns, thereby exposing fraudulent charges. Therefore, conducting decision support systems, such as ANN technology, to 
analyze the customer data should be a critical step toward CRM adoption in Taiwan's banking industry.

To sum up, past research suggests six factors that might affect the success of CRM adoption in Taiwan's banking industry: (1) primacy of customer service, (2) customizing CRM functions/modules, (3) discovering customers' needs, (4) maintaining employee's moral and (5) conducting a decision support system.

\section{RESEARCH DESIGN}

\section{Research Population And Samples}

The population of this survey is defined as "the local banking industry in Taiwan, including domestic banks and the local branches of foreign banks." The total number was seventy-two, including 41 domestic banks and 31 local branches of foreign banks. The information about these banks came from the official website of the Financial Supervisory Commission, Executive Yuan, Taiwan, Republic of China. The samples consisted of the CRM users in the Information-Technology or Customer-Service departments in those banks.

\section{The Hypothesis And Variables}

The review and discussion so far have laid the foundation for the following hypothesis:

Hp: The five predictor variables (i.e., primacy of customer service, customizing CRM functions/modules, discovering customers' needs, maintaining employee's moral, conducting a decision support system.) are most critical factors in improving the CRM deployment in Taiwan's banking industry.

\section{RESULTS AND DISCUSSION}

\section{Responses To The Survey}

Emails with online survey web link were sent to the identified participants. In addition to the email/online survey approach and with the helps from several banks' senior managers, the drop-off surveys were conducted in which 157 people were asked to fill out the questionnaires and 131 participants were able to complete the questionnaires.

To sum up, data were gathered from a total 161 respondents (i.e. 30 from the web-based online survey and 131 from the drop-off survey). To ensure the data consistency from these two collected datasets, a descriptive statistical analysis was conducted. The results from the analysis indicated that the mean and standard-deviation values from these two datasets (i.e. online and drop-off surveys) were sufficiently close and similar. The authors assumed the data collected from these two approaches were consistent and therefore merged them for further statistical analyses.

\section{Pre-Analysis Data Screening}

An evaluation of missing data and outliers (i.e., extreme values) of the collected data set led to the elimination of 16 cases, reducing the number of responses to 145 for further statistical analyses. The test of data normality, linearity, and homoscedasticity were also conducted in order to satisfy the general assumptions in multivariate statistical testing. Mertler and Vannatta (2005) suggested that "when the assumptions of linearity, normality, and homoscedasticity are met, residuals will create an approximate rectangular distribution with a concentration of scores along the center" (p.55). The scatterplot revealed that the residual plot created a rectangle shape with scores concentrated in the center, suggesting that the collected data set had satisfied the general assumptions of normality, linearity, and homoscedasticity in multivariate statistical testing. 
Figure 1 Scatterplot of present study

Scatterplot

Dependent Variable: Operational_efficiency

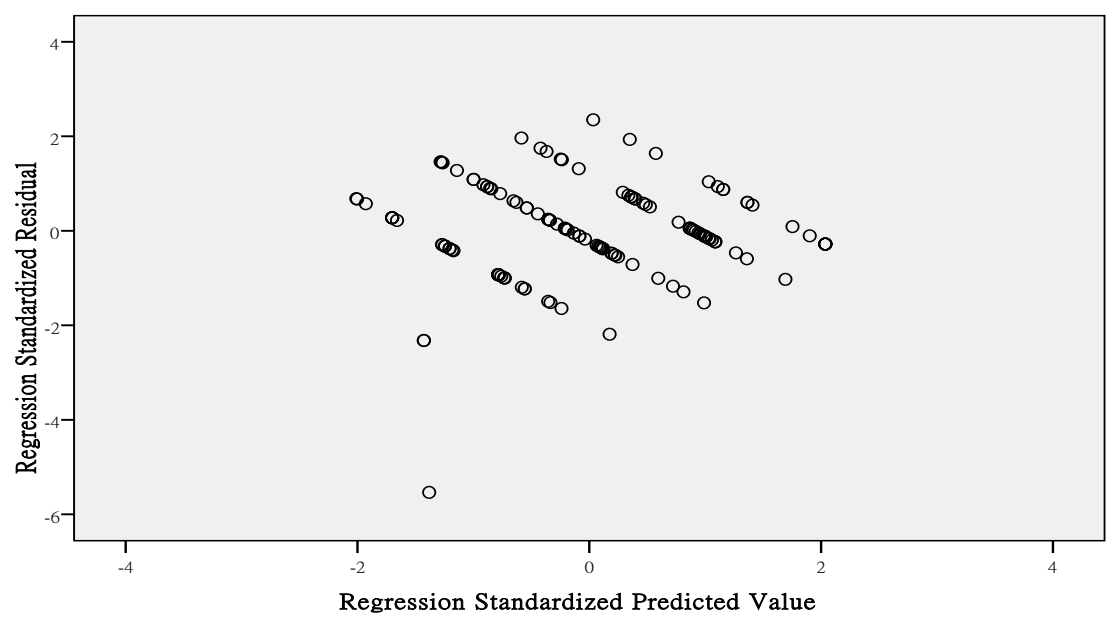

\section{Statistical Results}

The general models represent three primary parts of a multiple regression output using the standard regression approach (as opposed to the step-wise approach): Model Summary and Coefficients for Final Model. A review of the tolerance statistics presented in the coefficients table indicates that all IVs were tolerated in the model (with the tolerance statistics exceeding 0.1). Mertler and Vannata (2005) explain, "...if the tolerance value for a given IV is less than 0.1, multicollinearity is a distinct problem" (p. 169). Thus, collinearity is not a serious problem for the current data. The model summary indicate that the overall model of the ten IVs is significantly related to the operational efficiency [Adjusted $\mathrm{R}^{2}=.383, \mathrm{~F}(5,140)=19.011, \mathrm{p}<.0001$ ]. Therefore, the hypothesis, that the five predictor variables (i.e., primacy of customer service, customizing CRM functions/modules, discovering customers' needs, maintaining employee's moral, conducting a decision support system.) are critical factors in improving the CRM deployment in Taiwan's banking industry is supported.

The general model of the hypothesis of present study:

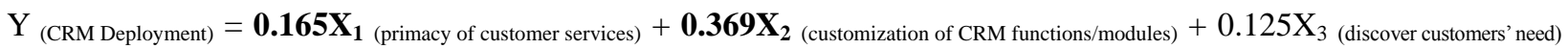
$+0.017 \mathrm{X}_{4}$ (keep employees' moral) $+0.118 \mathrm{X}_{5}$ (conduct the DSS)

Moreover, if banks in Taiwan wish to have a successful CRM deployment, they should concentrate on the following two variables as the most important factors when implementing a CRM project: primacy of customer service and customizing CRM functions/modules.

Table 1. Model Summary

\begin{tabular}{ccccccccc}
\hline Model & $\boldsymbol{R}$ & $\boldsymbol{R}^{2}$ & $\boldsymbol{R}^{2}{ }_{a d j}$ & $\Delta \boldsymbol{R}^{2}$ & $\boldsymbol{F}_{c h g}$ & $\boldsymbol{p}$ & $\boldsymbol{d f 1}$ & $\boldsymbol{d f 2}$ \\
\hline 1 & .636 & .404 & $\mathbf{. 3 8 3}$ & .404 & 19.011 & $<.0001$ & 5 & 140
\end{tabular}


Table 2. Coefficients for Final Model

\begin{tabular}{|l|l|c|c|c|c|}
\hline \multicolumn{2}{|l|}{ Model } & & & \multirow{2}{*}{ Tolerance } & Sig. \\
\hline & & Beta & T & & .259 \\
\hline & (Constant) & & 1.134 & .611 & .050 \\
\hline & Primacy_customer_service & $\mathbf{. 1 6 5}$ & 1.974 & .612 & .000 \\
\hline & Customization & $\mathbf{. 3 6 9}$ & 4.424 & .599 & .141 \\
\hline & Customer_need & .125 & 1.479 & .597 & .844 \\
\hline & Moral & .017 & .197 & .527 & .192 \\
\hline
\end{tabular}

\section{CONCLUSION}

Earlier in this article, a difference in customizing the CRM system between the Taiwan companies and their U.S. counterparts is mentioned. In United States customization is not widely applied while companies in Taiwan are more likely to customize their CRM systems in order to satisfy their customers' needs. Chang (2003, p. 55) suggests that the project managers should customize the CRM systems, meet the interface requirements, and conduct data conversion when adopting business intelligence systems such as CRM. Chang further admonishes companies to establish stable and long-term relationships with their customers through customization software designing. Moreover, Lai (2006) believes that the CRM systems, with the aid of integrated and well-established information technologies in financial-service firms, could gather and analyze customer-related information, develop forecasting models, ensure real-time responses and establish effective customized communication channels. Again, these observations reinforce the present study's finding: managers in Taiwan's banking industry should emphasize more on customizing the CRM functions and/or modules and privacy of customer service.

\section{AUTHOR INFORMATION}

C. P. Lin received his master degree in business administration from Northwestern Polytechnic University, Fremont, CA in 2006. He is now pursuing his DBA degree and currently a Teaching Assistant at the business school in Northwestern Polytechnic University, Fremont, CA. His current research interest includes customer relationship management and related information technology.

Y. H. Huang received his doctoral degree in business administration (DBA) from Golden Gate University, S.F., CA, in 2004. He has had more than 10 years of experience in directing and consulting projects involving e-business, enterprise systems, database systems for business applications, and network systems. He has also been involved in academic planning and teaching in colleges since 1995.

C. T. Chen is currently faculty at the Department of Information Management, Fortune Institute of Technology, Kaohsiung, Taiwan, R.O.C. His current research interest focuses on customer relationship management.

H. Y. Chang holds a M.S in Marketing and M.B.A in Management from Golden Gate University, CA in 2005. She is now pursuing her DBA degree and currently a Teaching Assistant at the business school in Northwestern Polytechnic University, Fremont, CA. Her current research interest includes senior care market and related company strategic management.

\section{REFERENCES}

1. Allen, P. (2002). How to create customer value in five simple steps. Chemistry \& Industry, Vol. 17, pp. 11.

2. Born, C. (2003). What makes a good CRM package? Retrieved July 10, 2007, from Computerworld Website: http://www.computerworld.com/action/article.do?command=viewArticleBasic\&articleId=81971 
3. Chang, B. S. (2003). The advantages and critical successful factors of introducing customer relationship management system. Unpublished master's thesis, Chung Yuan Christian University, Chung Li, Taiwan.

4. Chang, H. H. and Lin, S. C. (2002). Integrating of information quality and CRM: Evidence from financial organization. Journal of Information Management, Vol. 4, pp. 1-30.

5. Chang, K. and Liu, N. (2005). The effects of customer relationship programs on customer loyalty - an empirical study of Taiwan financial institutions. Commerce \& management quarterly, Vol. 6, pp. 491-514.

6. Cocheo, S. (2005). Back in balance. American bankers association. ABA banking journal, Vol. 97, pp. 7-87.

7. Coffey, J. and Palm, G. (2005). How to integrate your bank's profit system into your CRM? ABA Banking Marketing, Vol.37, pp.36.

8. Dobbins, J. (2006). The future of banking technology? Retrieved July 12, 2007, from BCS Web site: http://www.bcs.org/server.php?show=ConWebDoc.5851

9. Dorfman, R. (2006). Targeting high-value professionals. ABA bank marketing, Vol. 38, pp.32-36.

10. Earley, R. M. (2003). Foreshore: A Vision of CRM Outsourcing. Customer Inter@ction Solutions, Vol. 22, pp. 42-46.

11. Fadlalla, A. and Lin, C. (2001). An analysis of the applications of neural networks in finance. Interfaces, Vol. 31, pp. 112-122.

12. Fuller, L. (2005). A simple customer-retention strategy: securing direct deposits. ABA banking marketing, Vol. 37, pp. 47-48.

13. Gulledge, L. G. (1991). Satisfying the internal customer. Banking marketing, Vol. 21, pp. 46-48.

14. Hall, R. (2007). For the love of the game: out-loving the competition. ABA banking marketing, Vol. 39, pp. 16-17.

15. Harrison, W. and Hollingsworth, D. (1991). The core deposit intangible asset. Accounting horizons, Vol. 5, pp. 38-49.

16. Hormazi, A. M. and Giles, S. (2004). Data mining: a competitive weapon for banking and retail industries. Information systems management, Vol. 21, pp. 62-71.

17. Huang, C. C. and Lu, C. L. (2003). The processing functions and implementation factors of Customer Relationship Management Systems in the local banking industry. Journal of Information Management, Vol.5, pp.115-127.

18. Kincaid, J. W. (2003). Customer relationship management getting it right! Upper Saddle River, NJ: Prentice Hall PTR.

19. Kish, J. (2000). Before your customers leave... Banking marketing, Vol.32, pp.30-35.

20. Lai, K. Y. (2006). A study of CRM system from its current situation and effective factors perspectives. Unpublished master's thesis, National Central University, Chung Li, Taiwan.

21. Li, M. C. (2003). Object-oriented analysis and design for service-oriented customer relationship management information systems. Unpublished master's thesis, Chaoyang University of Technology, Taichung, Taiwan.

22. Lin, F. H. and Lin, P. Y. (2002). A Case Study of CRM Implementation: As Cathay United Bank an Example. $13^{\text {th }}$ International Conference on Information Management (pp. 527-534). Taipei: Taiwan.

23. Liao, S. J. (2003). The study of decision factors for customer relationship management implementation and customer satisfaction in Taiwan banking industry. Unpublished master's thesis, National Taipei University, Taipei, Taiwan.

24. Lian, T. (1993). Communication bankers conference offers competitive ideas. Banking marketing, Vol.25, pp.37-38.

25. Lu, K. L. (2000). The study in CRM systems adoption effective factors in Taiwnan's business. Unpublished master's thesis, National Taiwan University, Taipei, Taiwan.

26. Lu, H. P., Hsu, H. H., and Hsu, C. L. (2002). A study of the bank's establishment on Customer Relationship Management. $13^{\text {th }}$ International Conference on Information Management (pp. 535-542). Taipei: Taiwan.

27. Mertler, C. A. and Vannatta, R. A. (2005). Advanced and multivariate statistical methods: Practical application and interpretation. Los Angles: Pyrczak Publishing.

28. Motley, L. B. (2005). The benefits of listening to customers. ABA Banking Marketing, Vol.37, pp.43.

29. Mrazek, J. (2001). Fully integrated customer value management. BI report, December 2001.

30. Nagar, V. and Rajan, M. V. (2005). Measuring customer relationship: The case of the retail banking industry. Management science, Vol.51, pp.904-919. 
31. Penny, L. (1993). How do you catch a straying customer? American Bankers Association. ABA banking journal, Vol. 85, pp.66-70.

32. Peppers, D. and Rogers, M. (1993). The one to one future: Building relationships one customer at a time. New York: Bantam Doubleday Dell Publishing Group.

33. Robert, G. and Markey Jr. (2003). A four-step plan for keeping new customers in the fold. American Banker, Vo. 168 , pp.7.

34. Streeter, W. (1999). Value risk. American Banker Association. ABA Banking journal, Vol. 91, pp. 15.

35. Teng, C. Y. (2003). The research of relationship between customer relationship management system and operational strategies in Taiwan banking industry. Unpublished master's thesis, Chung Hua University, Hsinchu, Taiwan.

36. Turban, E., Aronson, J. E., and Liang, T. P. (2004). Decision support systems and intelligent systems (7 $7^{\text {th }}$ ed.). Upper Saddle River, NJ: Prentice Hall PTR.

\section{NOTES}




\section{NOTES}

